\title{
Pleural effusion as an indicator of short term mortality in acute pulmonary embolism
}

\author{
Şehnaz OLGUN \\ YILDIZELi ${ }^{1}$ \\ Umut Sabri KASAPOĞLU ${ }^{1}$ \\ Hüseyin ARIKAN ${ }^{1}$ \\ Canan ÇiMşiT ${ }^{2}$ \\ Nuri Çagatay ÇiMşī ${ }^{2}$ \\ Melek SÜZER ASLAN ${ }^{1}$ \\ Derya KOCAKAYA ${ }^{1}$ \\ Emel ERYÜKSEL ${ }^{1}$ \\ Berrin CEYHAN ${ }^{1}$ \\ Sait KARAKURT ${ }^{1}$
}

\footnotetext{
${ }^{1}$ Marmara Üniversitesi Tıp Fakültesi, Göğüs Hastalıkları ve Yoğun Bakım Anabilim Dalı, İstanbul, Türkiye

${ }^{1}$ Department of Chest Diseases and Critical Care, Faculty of Medicine, Marmara University, Istanbul, Turkey

${ }^{2}$ Marmara Üniversitesi Tıp Fakültesi, Radyoloji Anabilim Dalı, İstanbul, Türkiye

${ }^{2}$ Department of Radiology, Faculty of Medicine, Marmara University, Istanbul, Turkey
}

\section{SUMMARY}

Pleural effusion as an indicator of short term mortality in acute pulmonary embolism

Introduction: Pulmonary embolism (PE) is known as one of the major causes of cardiovascular morbidity and mortality. Identification of high risk patients for short term and long-term mortality is crucial. The purpose of this study is to demonstrate the prognostic importance of simplified pulmonary embolism severity index (SPESI), radiological investigations and comorbidities in terms of shortterm mortality by simultaneous assessment of SPESI score, pulmonary computed tomography (CT) angiography findings and underlying comorbidities in patients diagnosed with acute pulmonary embolism.

Materials and Methods: We retrospectively evaluated 570 patients diagnosed with acute PE confirmed by computer tomography pulmonary angiography (CTPA). Comorbidities were recorded, pulmonary embolism severity index scores were calculated and CTPA data were evaluated as predictors for short-term mortality.

Results: The study population consisted of 570 patients, $292(51.2 \%)$ patients were female and 74 patients (12.9\%) died within 30 days due to PE diagnosis. In univariate analysis male gender ( $p=$ $0.031)$, congestive heart failure $(C H F)(p<0.029)$, main pulmonary artery involvement $(p=0.045)$, presence of pleural effusion ( $p=$ $0.001)$ and pericardial effusion $(p=0.004)$ at time of diagnosis and high risk sPESI group $(p<0.001)$ had a significant influence on mortality. In the multivariate analysis, pleural effusions (HR, 1.67; $\mathrm{Cl}, 1.05-2.66 ; p<0.030)$ and sPESI high risk group $(\mathrm{HR}, 9.56 ; \mathrm{Cl}$, 4.71-19.43; $p<0.001$ ) were remained significant and independent

\section{Yazışma Adresi (Address for Correspondence)}

Dr. Şehnaz OLGUN YILDIZELI

Marmara Üniversitesi Tıp Fakültesi, Göğüs Hastalıkları ve Yoğun Bakım Anabilim Dalı, ISTANBUL - TÜRKIYE

e-mail: drsehnazolgun@yahoo.com prognostic factors for survival. 
Conclusion: The present study underlined that presence of pleural effusion at the time of diagnosis in patients with massive pulmonary embolism and a high SPESI score in other patients were significant predictors of short-term mortality.

Key words: Pulmonary embolism; pleural effusion; mortality; predictor

ÖZET

Akut pulmoner embolide erken dönem mortalitenin göstergesi olarak plevral efüzyon

Giriş: Pulmoner emboli (PE), kardiyovasküler morbidite ve mortalitenin başlıca nedenlerinden biri olarak bilinmektedir. Yüksek riskli hastaların belirlenmesi kısa dönem ve uzun dönem mortalitesi açısından çok önemlidir.

Materyal ve Metod: Bu çalışmanın amacı, akut pulmoner emboli tanııı alan hastalarda, basitleştirilmiş pulmoner emboli şiddet indeksinin (sPESI), radyolojik araştırmaların ve komorbiditelerin kısa dönem mortalitesi açısından prognostik önemini göstermektir. Bilgisayarlı tomografi pulmoner anjiyografi (BTPA) ile akut PE tanısı alan 570 hastayı retrospektif olarak değerlendirdik. Komorbiditeler kaydedildi, sPESI skorları hesaplandı ve BTPA verileri değerlendirildi.

Gereç ve Yöntem: Bilgisayarlı tomografi pulmoner anjiyografi (BTPA) ile akut PE tanısı alan 570 hastayı retrospektif olarak değerlendirdik. Komorbiditeler kaydedildi, sPESI skorları hesaplandı ve BTPA verileri değerlendirildi.

Bulgular: Çalışmaya alınan toplam 570 PE tanılı hastanın 292'si (\%51.2) kadındı, 74 hastada (\% 12.9) tanı aldıktan sonra 30 gün içinde öldü. Tek değişkenli analizde tanı anında ana pulmoner arter tutulumu $(p=0.045)$, plevral efüzyon varlı̆̆ $(p=0.001)$ ve perikardiyal efüzyon $(p=0.004)$ erkek cinsiyet ( $p=0.031)$, konjestif kalp yetmezliği $(K K Y)$ yüksek riskli sPESI grubu $(p<0.001)$ mortalite üzerinde anlamlı bir etkiye sahipti. Çok değişkenli analizde plevral efüzyon (HR, 1.67; Cl, 1.05-2.66; $p<0.030)$ ve sPESI yüksek risk grubu (HR, 9.56; CI, 4.71-19.43; $p<0.001)$ sağkalım üzerinde anlamlı ve bağımsız birer risk faktörü olarak saptandı.

Sonuç: Bu çalışma, akut pulmoner emboli tanısı alan hastalarda tanı anında plevral efüzyon varlığının varlığı ve yüksek riskli bir sPESI skorunun kısa dönem mortalitenin belirleyicileri olduğunun altını çizmektedir.

Anahtar kelimeler: Pulmoner emboli; plevral efüzyon; mortalite; belirteç

\section{INTRODUCTION}

Pulmonary embolism (PE) is known as one of the major causes of cardiovascular morbidity and mortality. Although the recent improvements in diagnostic methods increased the frequency of diagnosing PE and new treatment options and strategies have been developed both for acute and sub-acute phases of the disease, short and long-term mortality rates remain high $(1,2)$. Symptoms and signs of the disease at diagnosis, thus, its short-term prognosis may vary from patient to patient. Short-term mortality rate is known to be higher among patients who are hemodynamically instable or have right ventricular dysfunction (3). Risk classification and identification of risk factors for each patient are crucial both to determine the treatment strategy during acute phase of the disease and to reduce mortality in the long-term (4).

Currently, there are certain clinical scoring systems clinical aspects, cardiac biomarkers and imaging modalities used to allocate the patients to specific risk groups (5-8).

Risk status of patients with pulmonary embolism was determined based on pulmonary embolism severity index (PESI) score (5). This scoring system can allow prediction of short-term mortality based on practical clinical findings of patients diagnosed with PE.
Today, it is thought that the simplified PESI (sPESI) score expresses the comorbidity in cases diagnosed with PE. The european society of cardiology (ESC) emphasized that in the acute PE patients with stable hemodynamics, sPESI evaluation should be applied first in terms of prognosis.

Apart from PESI scoring in clinical practice, there are conflicting results regarding the effect of radiological findings, biomarkers and other comorbid conditions on mortality.

The purpose of this study is to demonstrate the prognostic importance of sPESI, radiological investigations and comorbidities in terms of short-term mortality by simultaneous assessment of PESI score, pulmonary computed tomography (CT) angiography findings and underlying comorbidities in patients diagnosed with acute pulmonary embolism.

\section{MATERIALS and METHODS}

\section{Study Design}

The study was approved by the clinical researches and ethics committee of Marmara University Medical School. This was a single-center, retrospective study carried out at a tertiary care-University hospital (Marmara University Hospital). All patients included in this study were diagnosed with acute symptomatic PE between January 2014 and July 2016. 
Patients with documented acute PE diagnosis as confirmed by computed tomography pulmonary angiography were identified from radiological data record system. Inclusion criteria were availability of full medical records including the time of admission and 30-day follow up. Totally 738 patients were diagnosed with PE and 168 of those were excluded from the study due to various reasons [14 patients had missing clinical data, 116 patients had a diagnosis of active malignancy (early stage, receiving curative treatment or advanced stage, receiving palliative treatment), 23 patients were followed by another center, 11 patients misused the medical treatment]. The treatment protocol and management were standardized according to the guidelines of European Society of Cardiology for the management of pulmonary embolism (9). Short-term mortality was defined as death secondary to cardiopulmonary arrest or respiratory failure within 30 days after PE diagnosis. Patients who died due to other causes were excluded (3 patients died from septic shock, 1 patient died from hepatotoxicity).

Final study group included 570 patients (Figure 1).

\section{Computed Tomography Examination}

All examinations were performed on a 256-slice scanner (Somatom Definition Flash, Siemens, Erlangen, Germany) with the following scan parameters: CARE Dose4D for automatic exposure control for tube voltage $(\mathrm{kV})$ and effective tube current $(\mathrm{mA})$, slices acquired with $128 \mathrm{~mm} \times 0.6 \mathrm{~mm}$ setting in the caudo- cranial direction, 0.5 pitch, and 0.28 -second rotation time. Field of view was adjusted to patient size, $512 \times$ 512 matrix was used, and mean scan time was $4.2 \mathrm{~s}$. Bolus tracking software was used with ROI cursor placed on RV with a setting of $50 \mathrm{HU}$ and a delay time of $3 \mathrm{~s}$, using $0.8 \mathrm{~mL} / \mathrm{kg}$ contrast agent $(350 \mathrm{mg} \mathrm{l} / \mathrm{mL})$ at $5 \mathrm{~mL} / \mathrm{s}$ delivery rate via antecubital line, followed by $20 \mathrm{cc}$ saline injection. Patients were instructed to cease normal breathing for $5 \mathrm{~s}$ on command right before starting the scan. Reconstructions included 0.75-mm-thick and 5-mm-thick image sets to evaluate arteries and the parenchyma, respectively.

All patient data were examined on a PACS system (Novapacs, Novarad Corporation, USA) by two radiologists who had 13 and 15 years of experience in chest radiology. Data obtained from all patients were reviewed independently by both radiologists and each radiologist documented his/her findings. Their data were then cross-matched and conflicting findings for clot localization $(n=8)$ were reevaluated together and a consensus was reached to resolve the discrepancies.

\section{Clinical Data-Comorbidities}

All historical clinical data were evaluated on the hospital's medical record system (MEDIN 3; version 33.19.909).

\section{Clinical Scores}

SPESI is a clinical score that has been established to predict short term mortality for PE (10). sPESI assesses six parameters (age $>80$ years, malignancy history,

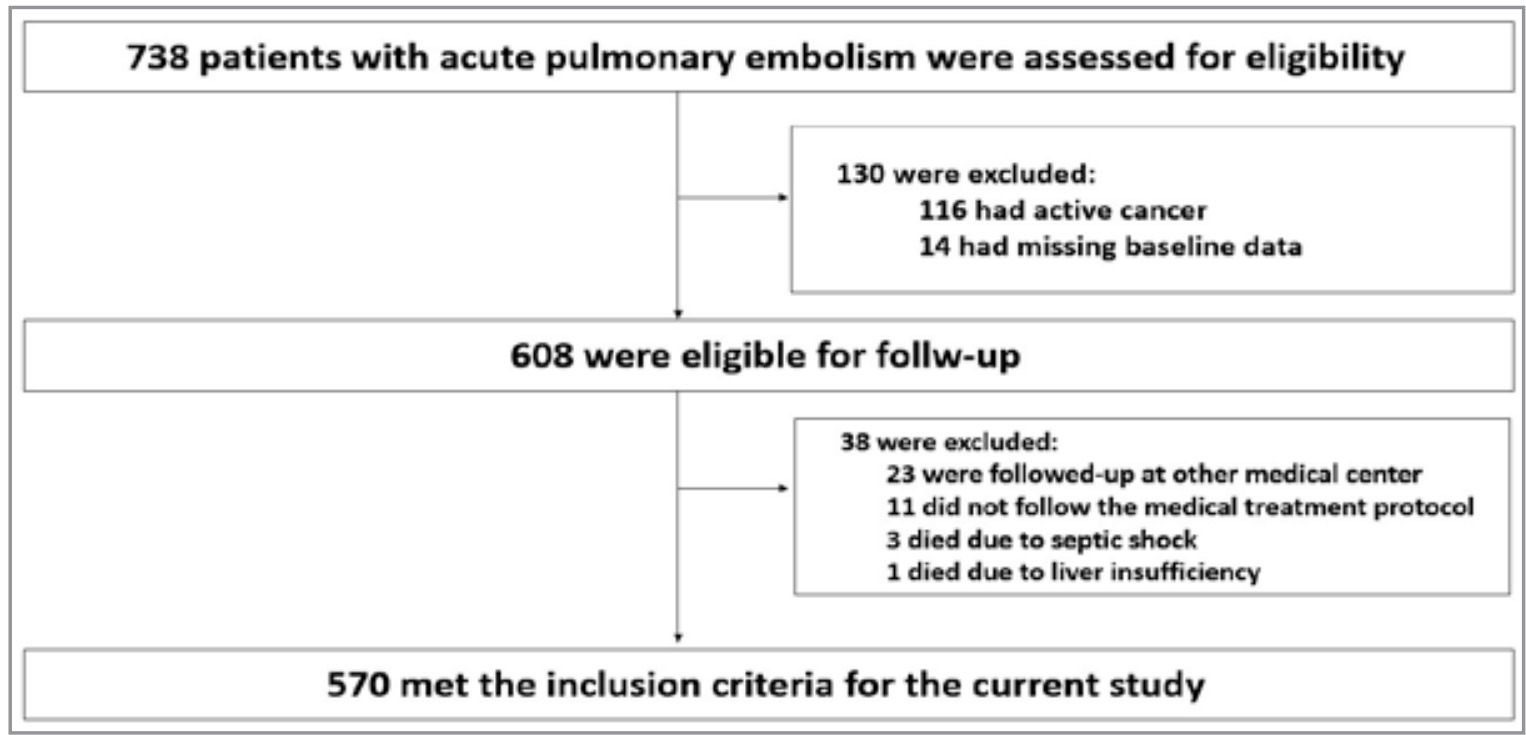

Figure 1. Flow diagram of study. 
cardiopulmonary disease history, heart rate $>110$ / min, systolic blood pressure $<100 \mathrm{mmHg}$, arterial oxygen saturation $>90 \%$ ). Each positive parameter was scored as 1 and scores of 1 and higher were considered as high-risk group and patients whose all parameters were negative evaluated as low-risk group.

\section{Classification of Emboli as Massive, Sub-massive and Non-massive}

The presence of hemodynamic instability at the time of diagnosis was assessed by hypotension. Hypotension is defined as a systolic blood pressure $<90 \mathrm{mmHg}$ or a drop in systolic blood pressure of $\geq 40 \mathrm{mmHg}$ from baseline for a period $>15$ minutes or hypotension that requires vasopressors or inotropic support and is not explained by other causes such as sepsis, arrhythmia, left ventricular dysfunction from acute myocardial ischemia or infarction, or hypovolemia. This group is classified as massive emboli. Patients with stable hemodynamics but right ventricular strain were classified as sub-massive emboli. Patients without right ventricular strain or hemodynamic instability were classified as non-massive emboli.

\section{Statistical Analysis}

Statistical analysis was performed using the Statistical Package for Social Sciences, version 20.0 for Windows program (SPSS Inc., Chicago, Illinois, USA). Data with normal and homogeneous distribution were presented as mean value \pm standard deviation while data without a normal and homogeneous distribution were shown as median (min-max) values as well as numbers and percentages. The distribution of variables was assessed using the Kolmogorov Simirnov test, and homogeneity using the one-way ANOVA. A t-test was used for analysis of parametric data, Mann Whitney $U$ test was used for analysis of non-parametric data, and Chi-square test was used for analysis of categorical data. The survival curve was calculated using the Kaplan-Meier method, and a log-rank test was used to compare the difference in survival between the groups. A logistic regression analysis, including all baseline characteristics, comorbidities, radiologic findings and sPESI values as independent variables, and mortality as the dependent variable, was performed. Cox regression analysis was used for multivariate survival analysis. The results were analyzed with a confidence level of $95 \%$, and a significance level of $p<0.05$.

\section{RESULTS}

\section{Demographical Data}

The study population consisted of 570 patients (median age 68 years, ranging from 19 to 89 years), 292 $(51.2 \%)$ patients were female and 74 patients $(12.9 \%)$ died within 30 days due to PE diagnosis.

Demographic data of the patients indicated that the median age of patients who died was significantly higher than that of the survivors [73 (32-85) vs 67 (1989); $p=0.010$ ], and patients older than 65 years had a more mortal disease course but it was not statistically significant [47 (63.5\%) vs. $267(41.2 \%) ; p=0.075$ ]. Also, male gender had a significant influence on mortality $(p=0.018)$ (Table 1$)$.

\section{Comorbidities}

Underlying comorbidities of the patients, including diabetes mellitus (DM), coronary artery disease (CAD), congestive heart failure (CHF), asthma, chronic obstructive pulmonary disease (COPD), hypertension, cerebrovascular disease, rheumatic diseases and chronic kidney disease (CKD) were evaluated. Frequencies of hypertension, CAD, CHF, DM and arrhythmias significantly differ among survived and deceased patients. But only frequency of CHF was found to be higher among deceased patients (Table 1).

\section{Radiological Investigations}

Localization of the embolism (sub-segmental, segmental, lobar, central artery), right ventricular (RV) diameter $(\mathrm{mm})$, pulmonary artery (PA) diameter $(\mathrm{mm})$, right ventricular diameter $(\mathrm{mm}) /$ left ventricular $(\mathrm{LV})$ diameter $>1$ ratio, presence of pleural effusion and presence of pericardial effusion were assessed in pulmonary CT angiography of all patients. Assessment of the relation between localization of the embolism and mortality showed that, among sub-segmental [126 $(22.1 \%)]$, segmental [261 $(45.8 \%)]$, lobar [110 $(19.3 \%)]$ and main pulmonary artery involvements [73 $(12.8 \%)]$, main pulmonary artery involvement caused a significant increase in mortality compared to the other localizations (15/74 vs. 58/496; $p=0.035)$; while none of the other localizations had a significant effect on mortality (Table 1).

Radiological investigations showed pleural effusion in $205(36 \%)$ patients. Comparison of the patients with 
Table 1. Demographics and characteristics of patients

\begin{tabular}{|c|c|c|c|c|}
\hline & $\begin{array}{c}\text { All patients } \\
(n=570)\end{array}$ & $\begin{array}{c}\text { Survivors } \\
(n=496)\end{array}$ & $\begin{array}{c}\text { Deceased } \\
(n=74)\end{array}$ & $p$ value \\
\hline Median age (min-max) & $68(19-89)$ & $67(19-89)$ & $73(32-85)$ & $0.010^{*}$ \\
\hline Age $>65$ years, $n(\%)$ & $314(55.1)$ & $267(53.8)$ & $47(63.5)$ & $0.075^{\#}$ \\
\hline \multicolumn{5}{|l|}{ Gender } \\
\hline Female, $\mathrm{n}(\%)$ & $292(51.2)$ & $263(53)$ & $29(39)$ & \multirow{2}{*}{$\mathbf{0 . 0 1 8}^{\#}$} \\
\hline Male, $\mathrm{n}(\%)$ & $278(48.8)$ & $233(47)$ & $45(61)$ & \\
\hline \multicolumn{5}{|l|}{ Comorbidities } \\
\hline Hypertension, n(\%) & $259(45.4)$ & $235(47.1)$ & $24(32.4)$ & $0.011^{\#}$ \\
\hline COPD, $n(\%)$ & $157(27.5)$ & $131(26.4)$ & $26(35.1)$ & $0.079^{\#}$ \\
\hline CAD, $n(\%)$ & $104(18.2)$ & $98(19.7)$ & $6(8.1)$ & $0.008^{\#}$ \\
\hline Diabetes mellitus, $\mathrm{n}(\%)$ & $95(16.7)$ & $88(17.7)$ & $7(9.4)$ & $0.047^{\#}$ \\
\hline $\mathrm{CHF}, \mathrm{n}(\%)$ & $87(15.3)$ & 69 (13.9) & $18(24.3)$ & $0.019^{\#}$ \\
\hline Arrhythmia, $\mathrm{n}(\%)$ & $80(14)$ & $75(15.1)$ & $5(6.7)$ & $0.033^{\#}$ \\
\hline Asthma, $\mathrm{n}(\%)$ & $36(6.3)$ & $34(6.8)$ & $2(2.7)$ & $0.128^{\#}$ \\
\hline Cerebrovascular disease, $\mathrm{n}(\%)$ & $33(5.8)$ & $29(5.8)$ & $4(5.4)$ & $0.569^{\#}$ \\
\hline Rheumatic diseases, $\mathrm{n}(\%)$ & $27(4.7)$ & $26(5.2)$ & $1(1.3)$ & $0.112^{\#}$ \\
\hline CKD, $n(\%)$ & $16(2.8)$ & $15(3)$ & $1(1.3)$ & $0.362^{\#}$ \\
\hline \multicolumn{5}{|l|}{ Radiological assessment } \\
\hline dPA mm (min-max) & $29(16-49)$ & $29(16-49)$ & $30(20-42)$ & $0.649^{*}$ \\
\hline $\mathrm{RV} / \mathrm{LV}>1, \mathrm{n}(\%)$ & $199(35)$ & $170(34.2)$ & $29(39.1)$ & $0.242^{\#}$ \\
\hline Pleural effusion, $\mathrm{n}(\%)$ & $205(36)$ & $165(33.2)$ & $40(54)$ & $0.001^{\#}$ \\
\hline Pericardial effusion, $\mathrm{n}(\%)$ & $40(7)$ & $28(4.6)$ & $12(16.2)$ & $\mathbf{0 . 0 0 3}^{\#}$ \\
\hline \multicolumn{5}{|l|}{ Radiologic classification } \\
\hline Central pulmonary artery, n(\%) & $73(12.8)$ & $58(11.6)$ & $15(20.2)$ & $0.035^{\#}$ \\
\hline Lobar pulmonary artery, n(\%) & $110(19.3)$ & $96(20.8)$ & $14(18.9)$ & $0.537^{\#}$ \\
\hline Segmental pulmonary artery, n(\%) & $261(45.8)$ & $226(45.5)$ & $35(47.2)$ & $0.438^{\#}$ \\
\hline Subsegmental pulmonary arter, n(\%) & $126(22.1)$ & $116(23.3)$ & $10(13.5)$ & $0.070^{\#}$ \\
\hline \multicolumn{5}{|l|}{ Scores } \\
\hline Mean sPESI score $( \pm$ STD) & $1.36(1.18)$ & $1.17(1.06)$ & $2.69(1.10)$ & $<0.001^{+}$ \\
\hline sPESI score: $0-1, n(\%)$ & $329(57.7)$ & $320(64.5)$ & $9(12.2)$ & \multirow{2}{*}{$<0.001^{\#}$} \\
\hline sPESI score: $2-5, \mathrm{n}(\%)$ & $241(42.3)$ & $176(35.5)$ & $65(87.8)$ & \\
\hline
\end{tabular}

and without effusion showed that the presence of effusion at the time of diagnosis was directly associated with mortality (40/74 vs. $165 / 496 ; p=0.001)$. Also, comparison of the patients with and without pericardial effusion showed that the presence of pericardial effusion at the time of diagnosis was associated with mortality (12/74 vs. 28/496; $p=0.003)$ (Table 1$)$.

\section{sPESI Score}

Mean sPESI score of the patients included in this study was 1.36 ( \pm 1.18$)$. Comparison of sPESI scores between patients who died and survived showed that the deceased patients had significantly higher sPESI scores [2.69 ( \pm 1.10$)$ vs. $1.17( \pm 1.06) ; p<0.001]$ (Table 1). According to sPESI categories, mortality in two catego- 
ries (low risk and high risk) were found to be $9 / 329$ $(2.7 \%)$ and $65 / 241$ (27\%), respectively; and sPESI high risk group indicated increased risk of mortality $(\mathrm{p}<$ 0.001).

Assessment of the factors predicting 30-days mortality in univariate analysis showed that male gender $(\mathrm{HR}$, $1.6695 \% \mathrm{Cl}, 1.04-2.65 ; \mathrm{p}=0.031), \mathrm{CHF}(\mathrm{HR}, 1.87 ; \mathrm{Cl}$, $1.10-3.18 ; p=0.029)$, sPESI high risk (HR, 11.34; $\mathrm{Cl}$, 5.6-22.78; $p<0.001$ ), presence of pleural effusion $(\mathrm{HR}, 2.24 ; \mathrm{Cl}, 1.42-3.54 ; \mathrm{p}<0.001)$, presence of pericardial effusion ( $\mathrm{HR}, 2.74 ; \mathrm{Cl}, 1.48-5.09 ; \mathrm{p}<0.004)$, and main pulmonary artery involvement $(H R, H R$, 1.84; $\mathrm{Cl}, 1.05-3.27 ; \mathrm{p}=0.045$ ) had a significant effect (Figure 2,3) (Table 2).

For multivariate analysis of factors affecting the survival of acute pulmonary embolism patients, the factors affecting the survival in the univariate analysis were included in the multivariate Cox regression analysis. It was shown that pleural effusions $(\mathrm{HR}, 1.67 ; \mathrm{Cl}, 1.05-$ $2.66 ; \mathrm{p}<0.030)$ and $\mathrm{sPESI}$ high risk group $(\mathrm{HR}, 9.56$; $\mathrm{Cl}, 4.71-19.43 ; \mathrm{p}<0.001)$ were significant and independent prognostic factors for survival (Table 3).

\section{Massive, Sub-massive and Non-massive Emboli}

There were $62(11 \%)$ massive, 208 (36.4\%) sub-massive and 300 (\%52.6) non-massive emboli patients. When the 30-day mortality of the groups were examined, it was found that the life span of non-massive group was longer than that of sub-massive and massive $(p<0.001)$ (Table 4). According to this classification; pleural and pericardial effusion was found more frequently in the massive group than in the other groups $(p<0.001, p=0.001)$. In patients with massive emboli, patients with sPESI scores between 2 to 5 were higher than the other groups $(p<0.001)$ (Table 5). In

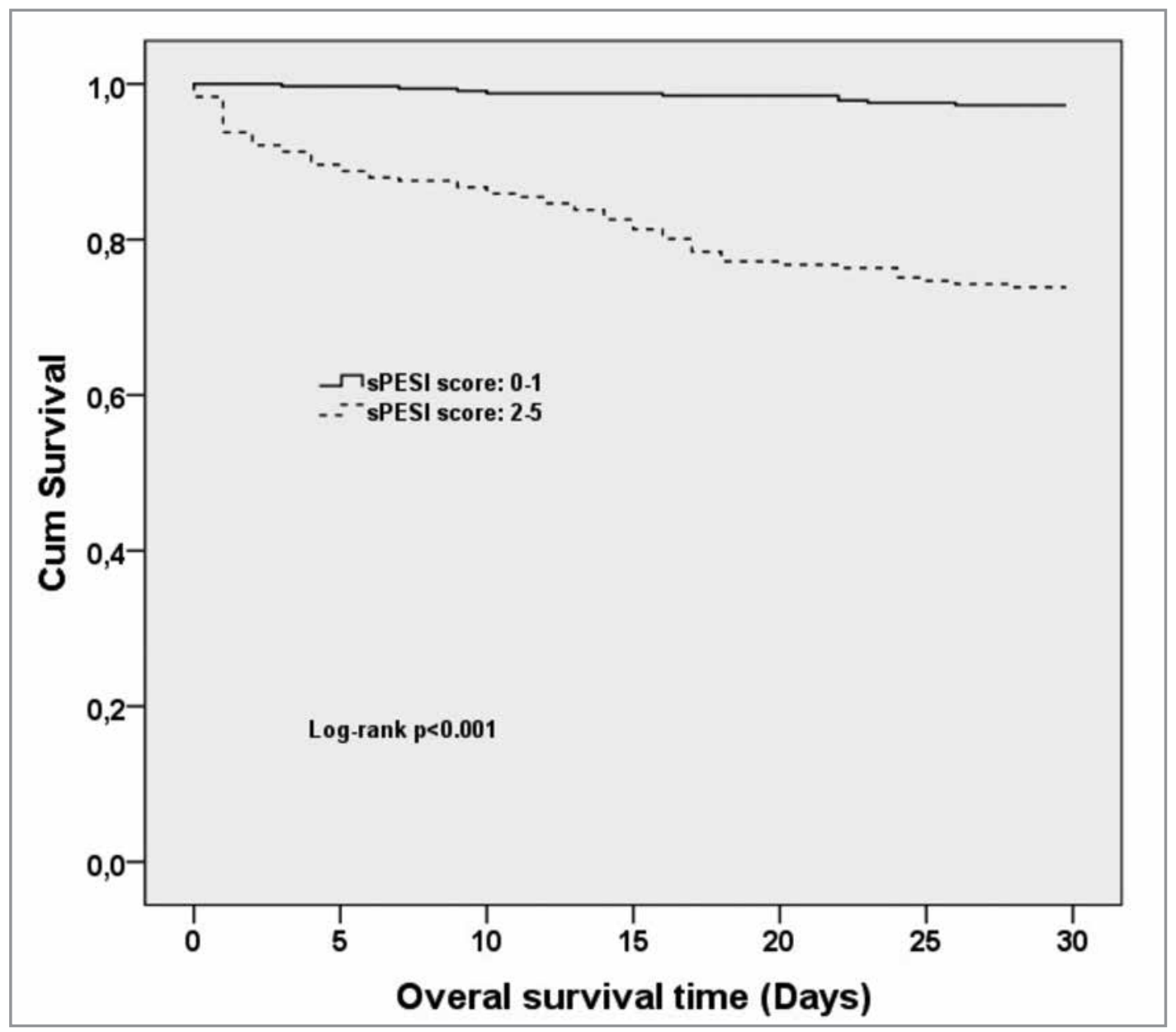

Figure 2. Kaplan-Meier curves of overall survival time for patients by sPESI score. 


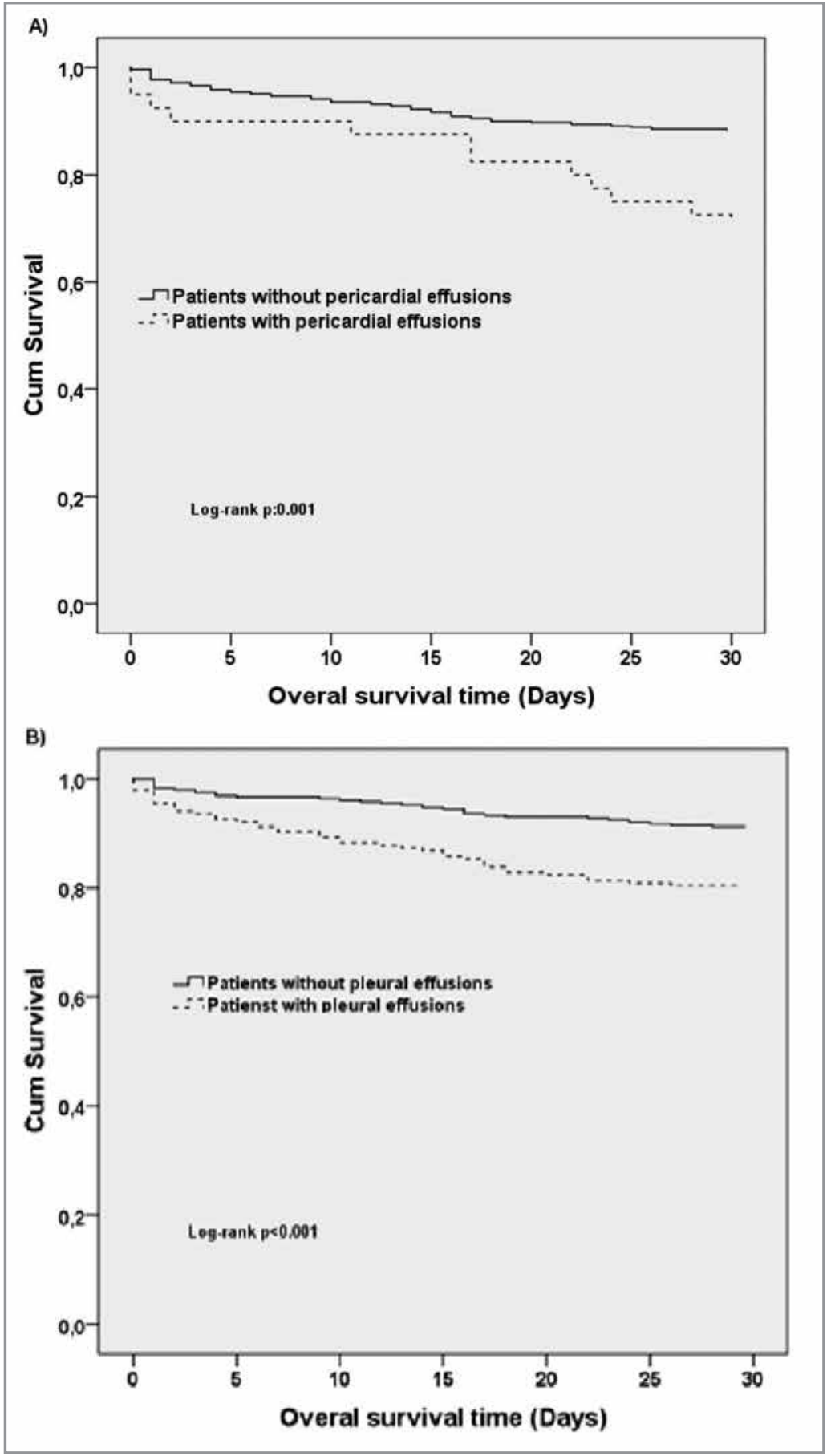

Figure 3. Kaplan-Meier curves of overall survival time according to A) presence/absence of pericardial effusions and B) presence/absence of pleural effusions in acute pulmonary embolism patients. 
Pleural effusion as an indicator of short term mortality in acute pulmonary embolism

Table 2. Univariate predictors of 30 days cardio-respiratory mortality in patients with acute pulmonary embolism

\begin{tabular}{|lccc|} 
& HR & $\mathbf{9 5} \% \mathbf{~ C l}$ & p value \\
\hline Gender & 1.66 & $1.04-2.65$ & $\mathbf{0 . 0 3 1}$ \\
Age & 1.44 & $0.90-2.32$ & 0.120 \\
COPD & 1.43 & $0.89-2.31$ & 0.144 \\
CHF & 1.87 & $1.10-3.18$ & $\mathbf{0 . 0 2 9}$ \\
Diabetes mellitus & 0.50 & $0.23-1.10$ & 0.059 \\
sPESI high score & 11.34 & $5.6-22.78$ & $\mathbf{0 . 0 0 1}$ \\
Pleural effusion & 2.24 & $1.42-3.54$ & $\mathbf{0 . 0 0 1}$ \\
Pericardial effusion & 2.74 & $1.48-5.09$ & $\mathbf{0 . 0 0 4}$ \\
Central pulmonary artery involvement & 1.84 & $1.05-3.27$ & $\mathbf{0 . 0 4 5}$ \\
RV/LV $>1$ & 1.23 & $0.77-1.96$ & 0.386 \\
\hline
\end{tabular}

HR: Hazard ratio, Cl: Confidence interval, COPD: Chronic obstructive pulmonary disease, CHF: Congestive heart failure, RV/LV $>1$ : Right ventricular diameter $(\mathrm{mm}) /$ left ventricular (LV) diameter $>1$ ratio, sPESI: Simplified pulmonary embolism severity index.

Table 3. Results of Cox regression analysis for multivariate analysis of survival factors

\begin{tabular}{|c|c|c|c|}
\hline & \multicolumn{3}{|c|}{ Multivariate analysis } \\
\hline & HR & $95 \% \mathrm{Cl}$ & $\mathbf{p}$ \\
\hline \multicolumn{4}{|l|}{ Gender } \\
\hline Male & \multirow{2}{*}{1.51} & \multirow{2}{*}{$0.94-2.419$} & \multirow{2}{*}{0.084} \\
\hline Female & & & \\
\hline \multicolumn{4}{|l|}{$\mathrm{CHF}$} \\
\hline Present & \multirow{2}{*}{1.05} & \multirow{2}{*}{$0.61-1.82$} & \multirow{2}{*}{0.838} \\
\hline Absent & & & \\
\hline \multicolumn{4}{|l|}{ sPESI score } \\
\hline$<1$ & \multirow{2}{*}{9.56} & \multirow{2}{*}{$4.71-19.43$} & \multirow[b]{2}{*}{$<0.001$} \\
\hline$>1$ & & & \\
\hline \multicolumn{4}{|c|}{ Pleural effusion } \\
\hline Present & \multirow[b]{2}{*}{1.67} & \multirow[b]{2}{*}{$1.05-2.66$} & \multirow[b]{2}{*}{0.030} \\
\hline Absent & & & \\
\hline \multicolumn{4}{|c|}{ Pericardial effusion } \\
\hline Present & \multirow{2}{*}{1.82} & \multirow{2}{*}{$0.97-3.41$} & \multirow{2}{*}{0.062} \\
\hline Absent & & & \\
\hline \multicolumn{4}{|c|}{ Central pulmonary artery involvement } \\
\hline Yes & \multirow{2}{*}{1.54} & \multirow{2}{*}{$0.87-2.73$} & \multirow{2}{*}{0.133} \\
\hline No & & & \\
\hline
\end{tabular}

patients with massive emboli; mortality rate was $74.1 \%$ in patients with pleural effusion and $48.3 \%$ in patients without pleural effusion ( $p=0.037$ ). In patients with sub-massive emboli; mortality was found to be as $19.8 \%$ in cases with high SPESI score and as $5.1 \%$ in cases with low sPESI score $(p=0.002)$. In non-massive emboli group, patients with high sPESI scores had a mortality rate of $7.1 \%$ whereas patients with low sPESI scores had mortality rate of $1.7 \%(p=0.020)$ (Table 6).

\section{DISCUSSION}

The present study evaluated the prognostic value of radiological findings, sPESI score and comorbidities in 
Table 4. Short term survival in massive, sub-massive and non-massive groups

\begin{tabular}{|lcccc} 
& Number of patients & Survival time (days) & $\mathbf{9 5 \%} \mathbf{C l}$ & p value \\
\hline Massive & 62 & 16.9 & $3.4-9.4$ & \\
Sub-massive & 208 & 27.9 & $10.1-12.8$ & $\mathbf{0 . 0 0 1}$ \\
Non-massive & 300 & 29.4 & $17.8-20.6$ & \\
\hline
\end{tabular}

Table 5. Pleural effusion, pericardial effusion and sPESI in massive sub-massive and non-massive groups

\begin{tabular}{|c|c|c|c|c|}
\hline & Massive & Sub-massive & Non-massive & p value* \\
\hline \multicolumn{5}{|c|}{ Pleural effusion } \\
\hline Present & $31(50)$ & $97(46.7)$ & $77(25.6)$ & \multirow{2}{*}{$<0.001$} \\
\hline Absent & $31(50)$ & $111(53.3)$ & $223(74.4)$ & \\
\hline \multicolumn{5}{|c|}{ Pericardial effusion } \\
\hline Present & $10(16.1)$ & $19(9.1)$ & $11(3.6)$ & \multirow{2}{*}{0.001} \\
\hline Absent & $52(83.9)$ & $189(90.9)$ & $289(96.4)$ & \\
\hline \multicolumn{5}{|l|}{ sPESI scores } \\
\hline $0-1$ & $2(3.3)$ & $97(46.9)$ & $230(76.6)$ & \multirow{2}{*}{$<0.001$} \\
\hline $2-5$ & $60(96.7)$ & $111(53.1)$ & $70(23.4)$ & \\
\hline
\end{tabular}

predicting short-term mortality among patients diagnosed with acute embolism.

Given the main results of study; in cases of acute pulmonary embolism in the univariate analysis male gender, diagnosis of $\mathrm{CHF}$, presence of pericardial effusion, presence of pleural effusion in patients with massive embolism, major pulmonary artery involvement, and high-risk group of sPESI scoring in patients with other than massive embolism were found to be risk factors for short-term mortality. In multivariate analysis presence of pleural effusion and being in high-risk sPESI group were found to be predictors of short-term mortality.

Previous studies have shown that pleural effusion can be detected in almost $60 \%$ of the cases at the time of acute pulmonary embolism diagnosis (11). Pleural effusion may develop through a number of different mechanisms in patients with pulmonary embolism. Ischemia, which develops in the region distal to the artery upon occlusion of the artery by the embolism, increases the amount of interstitial fluid in the lungs, and elevated right ventricular pressure secondary to the embolism triggers the formation of parietal pleural fluid $(12,13)$. Vascular damage, which develops during embolism independent of the above listed factors, increases cytokine release and this, in turn, leads to higher vascular permeability and fluid transition can occur from the lymphatic region to pleural cavity (12). Previous studies investigating pulmonary embolism indicated that the presence of pleural effusion is a strong evidence on the favor of embolism (14). In the present study, 205 of 570 (36\%) patients had pleural effusion and presence of pleural effusion was found to be a risk factor for mortality. Moreover, sPESI high risk group were associated with a higher probability of detecting pleural effusion.

The risk of developing pleural effusion was found to be elevated in older patients, and in patients having higher BMI and PESI scores in this study, whereas the underlying comorbidities were not significant risk factors for the development of effusion. Very limited number of studies investigated the effects of the presence of fluid on mortality in patients with acute pulmonary embolism. The first study on this topic was a recent study performed by Zhou et al., who reported a direct relation between mortality and the presence of pleural effusion at the time of PE diagnosis (15). However, contrary to our study, that study also included patients diagnosed with cancer and the incidence 
Table 6. Relationship between mortality, pleural effusion, pericardial effusion, sPESI and massive, sub-massive and non-massive embolism

\begin{tabular}{|c|c|c|c|}
\hline & Exitus & Alive & p value * \\
\hline & \multicolumn{3}{|c|}{ Massive pulmonary embolism group } \\
\hline \multicolumn{4}{|l|}{ Pleural effusion } \\
\hline Present & 23 & 8 & \multirow{2}{*}{0.037} \\
\hline Absent & 15 & 16 & \\
\hline \multicolumn{4}{|c|}{ Pericardial effusion } \\
\hline Present & 8 & 2 & \multirow{2}{*}{0.185} \\
\hline Absent & 30 & 22 & \\
\hline \multicolumn{4}{|l|}{ sPESI score } \\
\hline 0-1 point & 0 & 2 & \multirow{2}{*}{0.070} \\
\hline \multirow[t]{2}{*}{ 2-5 point } & 38 & 22 & \\
\hline & \multicolumn{3}{|c|}{ Sub-massive pulmonary embolism group } \\
\hline \multicolumn{4}{|l|}{ Pleural effusion } \\
\hline Present & 13 & 84 & \multirow{2}{*}{0.866} \\
\hline Absent & 14 & 97 & \\
\hline \multicolumn{4}{|c|}{ Pericardial effusion } \\
\hline Present & 3 & 16 & \multirow{2}{*}{0.702} \\
\hline Absent & 24 & 165 & \\
\hline \multicolumn{4}{|l|}{ sPESI score } \\
\hline 0-1 point & 5 & 92 & \multirow{2}{*}{0.002} \\
\hline \multirow[t]{2}{*}{$2-5$ point } & 22 & 89 & \\
\hline & \multicolumn{3}{|c|}{ Non-massive embolism group } \\
\hline \multicolumn{4}{|l|}{ Pleural effusion } \\
\hline Present & 4 & 73 & \multirow{2}{*}{0.190} \\
\hline Absent & 5 & 218 & \\
\hline \multicolumn{4}{|c|}{ Pericardial effusion } \\
\hline Present & 1 & 10 & \multirow{2}{*}{0.228} \\
\hline Absent & 8 & 281 & \\
\hline \multicolumn{4}{|l|}{ sPESI score } \\
\hline 0-1 point & 4 & 226 & \multirow{2}{*}{0.020} \\
\hline $2-5$ point & 5 & 65 & \\
\hline
\end{tabular}

of, as well as the mortality due to effusion was found to be elevated in that patient group. Similar to our study, Kiris et al. very recently reported that the presence of pleural effusion in patients diagnosed with PE can be a risk factor for short and long-term mortality. Again, contrary to our study, that study included patients with different malignancies and evaluated the amount of fluid. The authors reported a significantly higher rate of mortality in patients with bilateral effusion and in groups with moderate and excess levels of fluid (16). In this study, the univariate and multivariate analysis both showed that pleural effusion alone was significant in terms of predicting mortality in patients with massive embolism.

On the radiological evaluation, pericardial effusion was detected in 74 patients and it was shown as a risk factor for early mortality in univariate analysis but did not reach the level of significance in multivariate analysis. Although there are reports of pericardial effusion in the pulmonary embolism, there is no other study in the literature that examines the relationship 
between the presence of pericardial effusion and short-term mortality in PE.

Radiological data demonstrated that the localization of the embolism had an impact on mortality and the risk was elevated in the presence of central embolisms. In the meta-analyses performed by Vedovati et al. and Choi et al., a direct relation was established between central PE diagnosis and 30-days mortality $(17,18)$. However, the relation between RV/LV ratio and increased mortality, as demonstrated by those studies, was not confirmed in the present study. In line with our findings, recent systemic meta-analyses and reviews of patients with PE also did not indicate a relation between short-term mortality and morphometric measurements obtained by $\mathrm{CT}$ angiography $(8,19)$. Another study investigating the relation between $\mathrm{PE}$ and morphometric measurements reported a significantly higher frequency of RV/LV ratio among PE negative cases as well, thus the authors concluded that this parameter alone cannot be relevant for PE $(14,20)$. Similarly, Jimenez et al. argued that the CT angiography measurements alone cannot reflect the correct right heart functions and the findings should be confirmed by echocardiography (21). Measurements of the pulmonary artery diameter showed that the mean PA diameter was increased in the presence of centrally localized embolisms, however the difference did not reach the level of significance for mortality.

Chronic cardiac disorders and chronic respiratory diseases are questioned to estimate PESI score for the assessment of disease severity in patients diagnosed with PE. In addition to PESI score, the underlying chronic diseases were assessed in eight sub-categories in the present study. Congestive heart failure is detected as a risk factor for early mortality in the univariate analyses, however in multivariate analyses $\mathrm{CHF}$ did not continue to be significant. Contrary to the previous studies, the diagnoses of coronary artery disease and chronic obstructive pulmonary disease were not to be found associated with mortality $(5,9)$. Some of the studies concluded that the diagnosis of comorbidities like COPD represented a risk factor for long-term mortality, although it did not have any significant effect on the short-term mortality (16).

According to SPESI scores, mortality rate was higher among patients in high risk group compared to those in low risk group. There are several meta-analyses reporting the effectiveness of SPESI scoring in predicting short- and long-term mortality in patients diag- nosed with embolism $(22,23)$. In a recent study, Kumamaru et al. suggested a new scoring system based on thorax CT findings in patients diagnosed with acute pulmonary embolism (24). Based on their findings, the authors argued that a scoring system depending on radiological data was more successful than SPESI scoring in predicting short-term mortality. However, there are still only a limited number of studies supporting these findings.

Limitations of the present study include its retrospective design, missing laboratory data such as troponin, brain natriuretic peptide, absence of echocardiography reports, missing long term mortality results. Pleural and pericardial effusions detected in patients were considered as a result of pulmonary embolism with regard to clinical and laboratory findings. In this case it can be accepted as an additional bias. Moreover, lack of fluid amount assessments and biochemical or cytological examinations can be listed as additional limitations of this study.

In conclusion, the present study underlined that male gender, presence of pleural effusion in patients with massive embolism, pericardial effusion, sPESI high risk group in patients with other than massive embolism, main pulmonary artery involvement were significant risk factors of short-term mortality in patients diagnosed with acute pulmonary embolism. Compared to other comorbidities $\mathrm{CHF}$ was found to be more significant in terms of short-term mortality. Pleural effusion and sPESI high risk group are both strong predictors of short term mortality in acute pulmonary embolism. Additional studies including larger patient populations are required to better demonstrate the aforementioned effect of pleural effusion.

\section{REFERENCES}

1. Cohen AT, Agnelli G, Anderson FA, Arcelus JI, Bergqvist D, Brecht JG, et al. Venous thromboembolism (VTE) in Europe. The number of VTE events and associated morbidity and mortality. Thromb Haemost 2007;98:75664.

2. Ng AC, Chung T, Yong AS, Wong HS, Chow V, Celermajer $D S$, et al. Long-term cardiovascular and noncardiovascular mortality of 1023 patients with confirmed acute pulmonary embolism. Circ Cardiovasc Qual Outcomes 2011;4:122-8

3. Sanchez O TL, Colombet I, Durieux P, Huisman MV, Chatellier G. Prognostic value of right ventricular dysfunction in patients with haemodynamically stable pulmonary embolism: a systematic review. European Heart Journal 2008;29:1569-77. 
4. Dentali F, Cei M, Mumoli N, Gianni M. How to predict short- and long-term mortality in patients with pulmonary embolism? Pol Arch Med Wewn 2015;125:82-8.

5. Aujesky D, Obrosky DS, Stone RA, Auble TE, Perrier A, Cornuz J, et al. Derivation and validation of a prognostic model for pulmonary embolism. Am / Respir Crit Care Med 2005;172:1041-6.

6. Masotti L, Righini M, Vuilleumier N, Antonelli F, Landini G, Cappelli $R$, et al. Prognostic stratification of acute pulmonary embolism: focus on clinical aspects, imaging, and biomarkers. Vasc Health Risk Manag 2009;5:567-75.

7. Henzler T, Roeger S, Meyer M, Schoepf UJ, Nance JW Jr, Haghi D, et al. Pulmonary embolism: CT signs and cardiac biomarkers for predicting right ventricular dysfunction. Eur Respir J 2012;39:919-26.

8. Jimenez $D$, Lobo $L$, Monreal $M$, Moores $L$, Oribe $M$, Barron $M$, et al. Prognostic significance of multidetector $C T$ in normotensive patients with pulmonary embolism: results of the protect study. Thorax 2014;69:109-15.

9. Konstantinides SV, Torbicki A, Agnelli G, Danchin N, Fitzmaurice D, Galie N, et al. 2014 ESC guidelines on the diagnosis and management of acute pulmonary embolism. Eur Heart J 2014;35:3033-69, 3069a-3069k.

10. Jimenez D, Aujesky D, Moores L, Gomez V, Lobo JL, Uresandi F, et al. Simplification of the pulmonary embolism severity index for prognostication in patients with acute symptomatic pulmonary embolism. Arch Intern Med 2010; 170:1383-9.

11. Lobo IL, Zorrilla V, Aizpuru F, Uresandi F, Garcia-Bragado $F$, Conget $F$, et al. Clinical syndromes and clinical outcome in patients with pulmonary embolism: findings from the RIETE registry. Chest 2006;130:1817-22.

12. Findik S. Pleural effusion in pulmonary embolism. Curr Opin Pulm Med 2012;18:347-54.

13. Light RW. Pleural effusion due to pulmonary emboli. Curr Opin Pulm Med 2001;7:198-201.

14. Cimsit NC, Cimsit C, Onaygil C, Kuzan TY. Correlation of clot distribution with morphometric measurements and pleuroparenchymal findings in acute pulmonary embolism: experience with 692 cases. Clin Imaging 2015;39:1012-7.

15. Zhou $X$, Zhang Z, Zhai Z, Zhang Y, Miao R, Yang $Y$, et al. Pleural effusions as a predictive parameter for poor prognosis for patients with acute pulmonary thromboembolism. J Thromb Thrombolysis 2016;42:43240 .
16. Kiris T, Yazici S, Koc A, Koprulu C, Ilke Akyildiz Z, Karaca $M$, et al. Prognostic impact of pleural effusion in acute pulmonary embolism. Acta Radiol 2016.

17. Vedovati MC, Germini F, Agnelli G, Becattini C. Prognostic role of embolic burden assessed at computed tomography angiography in patients with acute pulmonary embolism: systematic review and meta-analysis. J Thromb Haemost 2013;11:2092-102.

18. Choi KJ, Cha SI, Shin KM, Lim JK, Yoo SS, Lee J, et al. Central emboli rather than saddle emboli predict adverse outcomes in patients with acute pulmonary embolism. Thromb Res 2014;134:991-6.

19. Trujillo-Santos J, den Exter PL, Gomez V, Del Castillo $H$, Moreno $C$, van der Hulle $T$, et al. Computed tomographyassessed right ventricular dysfunction and risk stratification of patients with acute non-massive pulmonary embolism: systematic review and meta-analysis. J Thromb Haemost 2013;11:1823-32.

20. Oz, II, Altinsoy B, Serifog/u I, Sayin R, Buyukuysal MC, Erboy $F$, et al. Evaluation of right atrium-to-right ventricle diameter ratio on computed tomography pulmonary angiography: Prediction of adverse outcome and 30-day mortality. Eur J Radiol 2015;84:2526-32.

21. Jimenez D, Lobo IL, Barrios D, Prandoni P, Yusen RD. Risk stratification of patients with acute symptomatic pulmonary embolism. Intern Emerg Med 2016;11:11-8.

22. Zhou $X Y$, Ben SQ, Chen HL, Ni SS. The prognostic value of pulmonary embolism severity index in acute pulmonary embolism: a meta-analysis. Respir Res 2012;13:111.

23. Dentali F, Riva N, Turato S, Grazioli S, Squizzato A, Steidl $L$, et al. Pulmonary embolism severity index accurately predicts long-term mortality rate in patients hospitalized for acute pulmonary embolism. J Thromb Haemost 2013;11:2103-10.

24. Kumamaru KK, Saboo SS, Aghayev A, Cai P, Quesada CG, George $E$, et al. CT pulmonary angiography-based scoring system to predict the prognosis of acute pulmonary embolism. J Cardiovasc Comput Tomogr 2016. 